\title{
RESB: 20 years of environmental science and bio/technology for sustainable development
}

\author{
Piet N. L. Lens
}

Published online: 13 February 2021

(C) The Author(s), under exclusive licence to Springer Nature B.V. part of Springer Nature 2021

For 20 years, Reviews in Environmental Science and Bio/Technology (RESB) has brought international perspective to important developments in the field of environmental science and (bio)technology. Throughout the years, the journal has summarised and interpreted knowledge and accelerated the development of technologies related to sustainability, clean energy, green mining, food security and water for all. RESB takes a uniquely integrated approach to environmental science and technology, bridging fundamental research with its environmental, industrial and societal applications. It has brought environmental research to an international readership of specialists, generalists, students, decision-makers and interested laypersons.

The environmental problems the world faces today are not new, but they are many and dynamic, and they vary tremendously in regions across the world. Rapid urbanization and the evolution of cities into megacities, population growth as well as climate variability and change are placing increasing demands and pressures on the world's environmental resources.

P. N. L. Lens $(\bowtie)$

National University Ireland, Galway, University Road, Galway H91 TK33, Ireland

e-mail: p.lens@un-ihe.org

P. N. L. Lens

IHE Delft Institute for Water Education, Westvest 7, 2611 AX Delft, The Netherlands
Over the past 20 years, RESB has synthesized research and development on mechanisms and technologies for chemical, physical and biological pollutant removal, shifting from pollution control towards cleaner technologies on the one hand and resource recovery on the other hand. Yet, despite massive progress over the past 20 years, access to safe drinking water, sanitation, electricity, proper waste management and healthy soils continues to be one of the major challenges for our society. This applies to both remote villages with poor or no public services as well as to cities that are overwhelmed by exploding population numbers. Environmental science and (bio)technology play a fundamental role in inclusive and sustainable economic growth, resilience to climate-related disasters, a healthy environment and ultimately to social well-being. RESB seeks to contribute to the understanding of how environmental technologies can combat these environmental problems and to provide resources which support technological innovations and evidence-based policy decisions.

Today's world is more inter-connected than ever. The challenges faced have transcended globally and require concerted action. To address this, the United Nations have set 17 Sustainable Development Goals (SDGs), designed to build a better world for the people and our planet by 2030. Innovative technologies allied to biological processes can produce bio-based renewable fuel sources and value added bio-based products, thereby helping to achieve sustainable practices. 


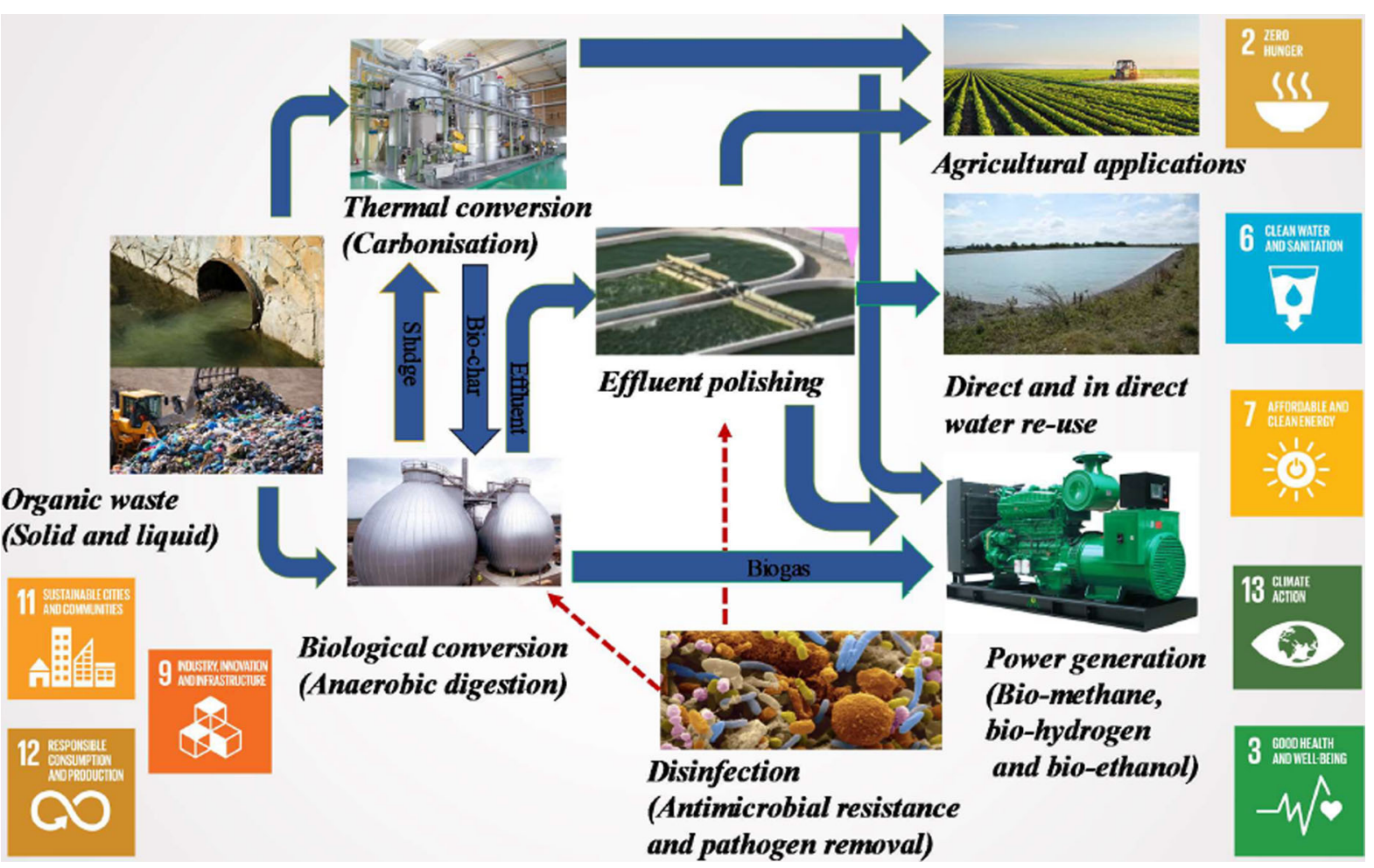

Fig. 1 Integrating bio-based treatment technologies with others to contribute to many SDGs while converting solid and liquid organic wastes to energy and value-added products (Ravishankar and Lens 2019)

Figure 1 shows how, for centralised wastewater treatment systems, along with addressing the different challenges, integration of technologies can help to achieve many key Sustainable Development Goals (SDGs), which include zero hunger (SDG 2), clean water and sanitation (SDG 6), affordable and clean energy (SDG 7), industry, innovation and infrastructure (SDG 9), sustainable cities and communities (SDG 11), responsible consumption and production (SDG 12), health and wellbeing (SDG 3) and climate action (SDG 13).

Translation of such schemes into the real world involves collaboration between research institutions (academia), industry and governments through successful pilot demonstrations and full-scale applications. Innovation ecosystems have been growing exponentially across the world in recent years: more or less high-tech manufacturers, start-ups and fablabs working on waste recycling, energy and mobility, find their way to contribute to local solutions of global problems. These innovations comprise both technological and social elements and emerge in both developed countries and countries in transition. For example, there are multiple alternatives to conventional models for electricity supply being adopted: ready-to-use home solar kits, energy kiosks, microgrids, .... These innovations can be commercial and contractual, with a massive success of prepay, payper-use and pay-as-you-go models, tailored to the amounts that people with low incomes can afford. This illustrates the role of mobile technology as a key enabler, notwithstanding the paradox that today more people have access to a mobile phone than access to a safe toilet. The views and reviews that RESB has published over the years illustrate that sustainable, circular economies are required to continue growth, while addressing environmental vulnerabilities. It is hoped that the publications in RESB in the past as well as the coming 20 years will contribute to the design of green, healthy, climate-resilient and inclusive (environmental) technologies, thus enabling the decarbonization of our economies, green growth in circular economies, and the building of climate-resilient communities. 


\section{Reference}

Ravishankar H, Lens PNL (2019) Achieving sustainable development goals (SDGs) through Ireland's bioeconomy. IETSBIO $^{3}$ Policy Brief series: No. 2, 25 April 2019
Publisher's Note Springer Nature remains neutral with regard to jurisdictional claims in published maps and institutional affiliations. 